\title{
Karaciğer fonksiyon testleri bozukluğu göstergesi olarak Manyetik Rezonans Kolanjiyopankreatografide minimal perihepatik sıvı varlığı
}

\author{
Presence of minimal perihepatic fluid in magnetic resonance cholangiopancreatography as a marker \\ of liver function test impairment
}

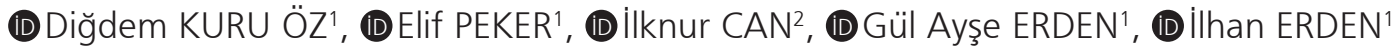 \\ Ankara Üniversitesi Tıp Fakültesi, ${ }^{1}$ Radyoloji Anabilim Dalı, Ankara

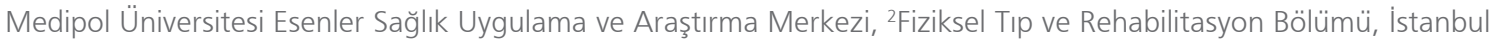

\begin{abstract}
Giriş ve Amaç: Karaciğer ve karaciğer dışı patolojilere bağlı görüntülemede perihepatik alanda sIvı görülebilmektedir. Belirli bir patolojiye spesifik olmayan bu durum değişik mekanizmalar ile oluşabilmektedir. Bu çalışmanın amacı manyetik rezonans kolanjiyopankreatografide minimal perihepatik sIVı varlığı ile karaciğer fonksiyon testleri ve manyetik rezonans kolanjiyopankreatografide ortaya koyulabilecek etiyolojik faktörlerden olan biliyer obstrüksiyon ile arasındaki ilişkiyi araştırmaktır. Gereç ve Yöntem: Hastanemiz Radyoloji bölümünde 2017 yilında manyetik rezonans kolanjiyopankreatografi yapılan hastalar retrospektif olarak tarandı. Minimal perihepatik sIVIsı olan 62 hasta çalışma grubuna, perihepatik sIVISI olmayan ve rastgele seçilen 62 hasta kontrol grubuna dahil edildi. Hasta ve kontrol grubuna ait karaciğer fonksiyon testleri (aspartat aminotransferaz, alanin aminotransferaz, alkalen fosfataz, gama-glutamil transpeptidaz, laktat dehidrogenaz, total/direkt/ indirekt bilirübin) karşılaştırıldı. Perihepatik sıvı kalınlığı, dağıım paterni, karaciğer loblarına göre lokalizasyonu, intrahepatik safra kanallarında genişleme varlığı ve derecesi, koledok taşı, periportal ödem, perisplenik sIVI varlığı kaydedildi ve perihepatik sıvı ile arasındaki ilişki değerlendirildi. Bulgular: Perihepatik sIVISI olan hasta grubunda laktat dehidrogenaz dışında tüm laboratuvar değerleri kontrol grubuna göre anlamlı olarak yüksekti ( $p=0.131$ ve $p \leq 0.011$, sırasıyla) ve perihepatik sIvIsı olan grupta kontrol grubuna göre daha fazla hastada laboratuvar değerlerinde yükseklik saptandı ( $p$ < 0.037). Intrahepatik safra kanallarında genişleme ve perisplenik sıvı varlığı açısından iki grup arasındaki fark istatistiksel olarak anlamlı idi ( $p=0.01$ ve $p<0.001$, sırasıly). Alkalen fosfataz değerleri ile intrahepatik safra kanalları genișleme derecesi korelasyon göstermekteydi $(r=0.349, p=0.05)$. Sonuç: Manyetik rezonans kolanjiyopankreatografide karaciğer çevresinde minimal düzeyde sıvı varlığı karaciğer fonksiyon testlerinde bozukluğa işaret edebilir ve kolestaza neden olabilecek patolojiler açısından uyarıcı olmalıdır.
\end{abstract}

Anahtar kelimeler: MRKP, perihepatik SIVI, karaciğer fonksiyon testi

\section{GíRiş}

Perihepatik sıvı, karaciğer çevresinde sıvı birikimi olup belirli bir duruma spesifik değildir. Karaciğer çevresinde biriken sıvı kan, lenf, safra, pankreatik salgı, idrar veya pü niteliğinde olabilir (1). Perihepatik sıvı birikiminde rol

Iletişim: Diğdem KURU ÖZ

Ankara Üniversitesi Tıp Fakültesi, Radyoloji Anabilim Dalı Ibni Sina Hastanesi 06100 Sihhiye/Ankara • Tel: +90 3125082511

Faks: +90 3123107117 • E-mail: digdem_k@hotmail.com
Background and Aims: Perihepatic fluid caused by liver and non-liver pathologies can be observed through imaging. This condition is not specific to a particular pathology and can occur with different mechanisms. This study aimed to investigate the relationship between the presence of minimal perihepatic fluid in magnetic resonance cholangiopancreatography and liver function tests and biliary obstruction, which is one of the etiological factors that can be detected through magnetic resonance cholangiopancreatography. Materials and Methods: Patients who underwent magnetic resonance cholangiopancreatography in the department of radiology in our hospital in 2017 were retrospectively screened. Sixty-two patients with minimal peripheral fluid were included in the study group, and randomly selected 62 patients without perihepatic fluid were included in the control group. Liver function tests (aspartate aminotransferase, alanine aminotransferase, alkaline phosphatase, gamma-glutamyl transpeptidase, lactate dehydrogenase, total/direct/indirect bilirubin) of the patient and control groups were compared. Perihepatic fluid thickness, distribution pattern, localization according to liver lobes, presence and degree of intrahepatic bile duct dilatation, and presence of choledocholitiasis, periportal edema, perisplenic fluid were recorded, and the relationship with perihepatic fluid was evaluated. Results: All laboratory values except lactate dehydrogenase were significantly higher in the patient group than in the control group ( $p=0.131$ and $p \leq 0.011$, respectively). The number of patients with higher laboratory values was higher in the patient group than in the control group $(p \leq 0.037)$. The difference between the two groups as regards intrahepatic bile duct dilatation and presence of perisplenic fluid was significant $(p=0.01$ and $p<0.001$, respectively). Alkaline phosphatase values correlated with the degree of intrahepatic bile duct dilatation $(r=0.349, p=0.05)$. Conclusions: The presence of minimal fluid around the liver detected by magnetic resonance cholangiopancreatography may indicate impairment in liver function tests and should alert clinicians of pathologies that can cause cholestasis.

Key words: $M R C P$, perihepatic fluid, liver function test

oynayan etkenler: negatif subdiyafragmatik basınç, karaciğerin anatomik bağlantıları, yer çekimi ve lenfatik dolaşımdır (1-3). Bunların içinde, özellikle karaciğer lenfatik dolaşımının önemli yeri vardır.Vücut lenf sıvısının büyük Kuru Öz D, Peker E, Can l, et al. Presence of minimal perihepatic fluid
in magnetic resonance cholangiopancreatography as a marker of liver in magnetic resonance cholangiopancreatography as a marker of liver
function test impairment. The Turkish Journal of Academic Gastroenterology 2021;20:13-18. DOI: 10.17941/agd.927772

Geliş Tarihi: 26.04.2020 • Kabul Tarihi: 21.01.2021 
kısmı karaciğer tarafından üretilmekte olup duktus torasikusa ulaşan lenf miktarının yaklaşık \%25-50'si karaciğer kaynaklıdır (4). Hepatik lenfatik sıvı, sinüzoidlerden Disse aralığına geçen plazma komponentlerinden oluşur. Karaciğerde, portal, sublobüler ve yüzeyel sistem olmak üzere 3 lokasyonda bulunur $(5,6)$. Disse aralığındaki lenfatik sıvının $\% 80$ ve daha fazlası portal lenfatik damarlara drene olurken geri kalanı santral ven çevresindeki sublobüler lenfatik damarlara ve hepatositler arasındaki interstisyumdan geçerek yüzeyel kapsüler lenfatiklere drene olur $(7,8)$. Deneysel biliyer obstrüksiyon yapılmış çalışmalarda gösterildiği gibi perihepatik alanda sıvı birikiminden özellikle yüzeyel lenfatiklerin sorumlu olduğu düşünülmekte$\operatorname{dir}(9-11)$.

Gözlemlerimize göre, karaciğer fonksiyon bozukluğu olan hastalarda radyolojik görüntülemede tek bulgu perihepatik sıvı olabilmektedir. Bu çalışmanın amacı, manyetik rezonans kolanjiyopankreatografide (MRKP) minimal perihepatik sıvı varlığı ile karaciğer fonksiyon testleri ve MRKP'de ortaya koyulabilecek etiyolojik faktörlerden olan biliyer obstrüksiyon arasındaki ilişkiyi araştırmaktır.

\section{GEREÇ ve YÖNTEM}

\section{Çalışma Dizaynı}

Retrospektif bu çalışma için 04-231-18 protokol numarası ile kurumsal etik kurul onayı alınmıştır. Ocak 2017- Aralık 2017 tarihleri arasında Ankara Üniversitesi Tıp Fakültesi Radyoloji bölümünde gerçekleştirilmiş 688 MRKP incelemesi retrospektif olarak tarandı. Kronik karaciğer hastalığı, asit, pankreatit, transplantasyon ve geçirilmiş cerrahi öyküsü olan toplamda 269 hasta dışlandı. Minimal (kalınlığı $1 \mathrm{~cm}$ 'den az) perihepatik sıvısı olan 62 ardışık olgu, hasta grubu olarak belirlendi. Kontrol grubu, perihepatik SIVISI olmayan 357 MRKP incelemesi arasından, hasta grubu ile aynı sayıda olacak şekilde rastgele olarak seçildi.

\section{MR Çekim Tekniği}

Çekimler 1.5 Tesla MR cihazlarında (Optima 450, GE ve Aera, Siemens, Erlangen, Almanya) gerçekleştirilmiştir. Tüm olgulara standart MRKP protokolü (koronal T2 ağırlıklı SSFSE, aksiyel T2 ağırlıklı FSE, aksiyel T2 ağırlıklı yağ baskılı FSE, 3D aksiyel-koronal MRKP, radial kalın slab $F S E, b=50,400,800$ değerleri ile aksiyel difüzyon ağırlıklı görüntüler, aksiyel T1 ağırlıkı dual eko GRE sekansları) uygulanmıştır.

\section{MR Görüntü Analizi}

Tüm görüntüler, klinik bilgiden habersiz 2 radyolog tarafından (D.K.Ö. ve E.P.) konsensus ile değerlendirildi. Pe- rihepatik sıvı kalınlığı, dağılım paterni, karaciğer loblarına göre lokalizasyonu, intrahepatik safra kanallarında genişleme varlığı ve genişleme derecesi, koledok taşı, periportal ödem, perisplenik sıvı varlığı değerlendirildi. Perihepatik sıvı kalınlığı milimetre cinsinden ortalama değer olarak kaydedildi. Dağıım paterni fokal, kesintili, difüz şeklinde sınıflandırımış olup perihepatik tek bir alanda olması, fokal (Resim 1); tüm perihepatik alanı sıvar tarzda olması, difüz (Resim 2); ve birkaç alanda ancak devamlı şekilde
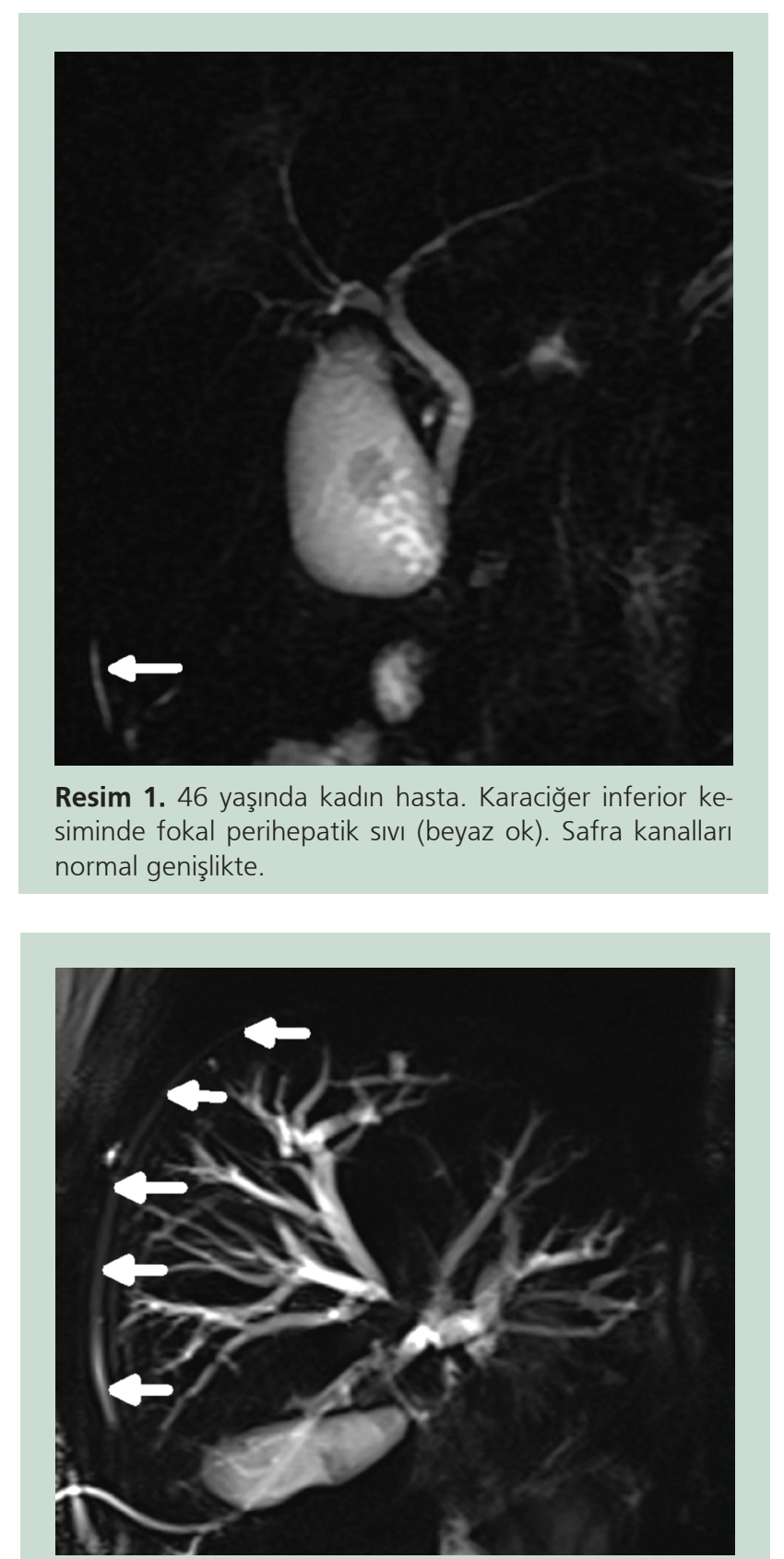

Resim 2. 38 yaşında erkek hasta. Perihepatik alanda difüz sıvar tarzda sıvı (beyaz oklar). Hepatik konfluens düzeyinde Klatskin tümörüne ikincil ana safra kanalında izlenememe ve intrahepatik safra kanallarında belirgin genişleme mevcut. 
olmaması durumunda kesintili (Resim 3) olarak değerlendirilmiştir. Loblara göre lokalizasyon, perihepatik sıvının karaciğer çevresinde ağırlıklı olduğu lokalizasyona göre sağ, sol veya eşit şeklinde sınıflandırıldı. İntrahepatik safra kanallarında genişleme varlığında genişleme derecesi subjektif olarak hafif ve belirgin şeklinde sınıflandırıldı. Hasta ve kontrol grubunun karaciğer fonksiyon testleri [aspartat aminotransferaz (AST), alanin aminotransferaz (ALT), alkalen fosfataz (ALP), gamaglutamil transpeptidaz (GGT), laktat dehidrogenaz (LDH), total/direkt/indirekt bilirubin] kaydedildi.

\section{İstatistiksel Analiz}

Verilerin analizi SPSS for Windows 11.5 (SPSS Inc, Chicago, IL, USA) programında yapılmıştır. Tanımlayıcı istatistikler dağılımı normal olan değişkenler için ortalama \pm standart sapma, dağııımı normal olmayan değişkenler için ortanca (min-maks), nominal değişkenler ise kişi sayısı (n) ve yüzde (\%) olarak gösterilmiştir. Gruplar arasındaki farkın önemliliği, Ki-Kare/Mann-Whitney U Testi ile araştırılmışır. Hasta grubunda, sıvı kalınlığı ve intrahepatik safra kanallarındaki dilatasyon derecesi ile laboratuvar testleri arasındaki ilişki Spearman korelasyon testi ile de- ğerlendirilmiştir. $\mathrm{P}<0.05$ için sonuçlar istatistiksel olarak anlamlı kabul edilmiştir.

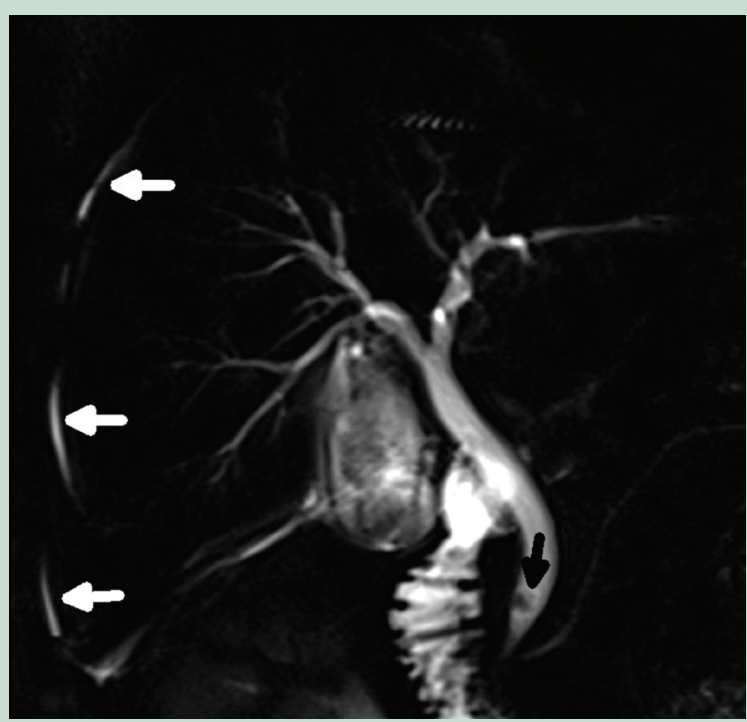

Resim 3. 44 yaşında erkek hasta. Perihepatik alanda kesintili vasıfta sıvı (beyaz oklar). Koledok distalinde taş (siyah ok) ve intrahepatik safra kanallarında hafif genişleme mevcut.

Tablo 1. Hasta ve kontrol grubundaki laboratuvar değerleri ve serum değerlerinde yükselme saptanan olguların sıklığı

\begin{tabular}{|c|c|c|c|c|c|c|}
\hline \multirow{3}{*}{$\begin{array}{l}\text { Laboratuvar } \\
\text { Testi (U/L, } \\
\mathrm{mg} / \mathrm{dL})\end{array}$} & \multirow{2}{*}{\multicolumn{2}{|c|}{$\begin{array}{l}\text { Yükselme Saptanan } \\
\text { Olgular, n (\%) }\end{array}$}} & \multirow{3}{*}{$p$} & \multirow{2}{*}{\multicolumn{2}{|c|}{ Serum Değeri }} & \multirow{3}{*}{$p$} \\
\hline & & & & & & \\
\hline & Hasta & Kontrol & & Hasta & Kontrol & \\
\hline AST $(>34)$ & $\begin{array}{c}33 \\
(53.2)\end{array}$ & $\begin{array}{c}14 \\
(22.6)\end{array}$ & $<0.001 *$ & $\begin{array}{c}37.5 \\
(13-340)\end{array}$ & $\begin{array}{c}21.0 \\
(7-354)\end{array}$ & $<0.001 *$ \\
\hline ALT $(>49)$ & $\begin{array}{c}35 \\
(56.5)\end{array}$ & $\begin{array}{c}15 \\
(24.2)\end{array}$ & $<0.001 *$ & $\begin{array}{c}48.0 \\
(9-779)\end{array}$ & $\begin{array}{c}22.5 \\
(8-726)\end{array}$ & $0.001 *$ \\
\hline GGT $(>38)$ & $\begin{array}{c}50 \\
(80.6)\end{array}$ & $\begin{array}{c}24 \\
(38.7)\end{array}$ & $<0.001 *$ & $\begin{array}{c}163.5 \\
(11-2070)\end{array}$ & $\begin{array}{c}28.0 \\
(5-767)\end{array}$ & $<0.001$ * \\
\hline $\mathbf{A L P}(>129)$ & $\begin{array}{c}42 \\
(67.7)\end{array}$ & $\begin{array}{c}14 \\
(23.3)\end{array}$ & $<0.001 *$ & $\begin{array}{c}158.0 \\
(27-1176)\end{array}$ & $\begin{array}{c}79.0 \\
(32-365)\end{array}$ & $<0.001 *$ \\
\hline LDH $(>246)$ & $\begin{array}{c}12 \\
(20.7)\end{array}$ & $\begin{array}{c}3 \\
(6.4)\end{array}$ & $0.037^{*}$ & $\begin{array}{c}191.0 \\
(20-906)\end{array}$ & $\begin{array}{c}175.0 \\
(132-354)\end{array}$ & 0.131 \\
\hline T. Bil $(>1.2)$ & $\begin{array}{c}26 \\
(43.3)\end{array}$ & $\begin{array}{c}7 \\
(11.9)\end{array}$ & $<0.001 *$ & $\begin{array}{c}0.90 \\
(0.28-13.30)\end{array}$ & $\begin{array}{c}0.65 \\
(0.26-6.94)\end{array}$ & $0.001 *$ \\
\hline D. Bil $(>0.3)$ & $\begin{array}{c}47 \\
(81.0)\end{array}$ & $\begin{array}{c}31 \\
(52.5)\end{array}$ & $0.001 *$ & $\begin{array}{c}0.31 \\
(0.10-9.83)\end{array}$ & $\begin{array}{c}0.20 \\
(0.05-4.90)\end{array}$ & $<0.001$ * \\
\hline i. Bil $(>0.8)$ & $\begin{array}{c}20 \\
(34.5)\end{array}$ & $\begin{array}{c}5 \\
(8.5)\end{array}$ & $0.001 *$ & $\begin{array}{c}0.62 \\
(0.10-6.63)\end{array}$ & $\begin{array}{c}0.45 \\
(0.18-2.59)\end{array}$ & $0.011^{*}$ \\
\hline
\end{tabular}

* İstatistiksel olarak anlamlı sonuçlar $(p<0.005)$

AST: Aspartat aminotransferaz, ALT: Alanin aminotransferaz, ALP: Alkalen fosfataz, GGT: Gamaglutamil transferaz, LDH: Laktat dehidrogenz T. Bil/D.Bil/I.Bil: Total/ Direkt/Indirekt bilirubin. 


\section{BULGULAR}

Çalışmamızda, 62 hasta ve 62 kontrol olmak üzere toplam 124 olgu (ortanca yaş 58, aralık 22-89 yıl; ortanca yaş 53, aralık 20-88 yıl, sırasıyla) retrospektif olarak değerlendirildi. Hasta grubunun 32'si (\%51.6) kadın, 30'u (\%48.6) erkek idi. Kontrol grubunu ise 37 (\%59.7) kadın, 25 (\%40.3) erkek oluşturmaktaydı. Hasta ve kontrol grubu arasında yaş açısından istatistiksel olarak fark var iken $(p=0.008)$, cinsiyet açııından anlamlı fark yoktu $(p=0.366)$. Perihepatik sIvIs olan hasta grubunda LDH dışında tüm laboratuvar değerleri kontrol grubuna göre anlamlı olarak yüksekti ( $p=0.131$ ve $p \leq 0.011$, sırasıyla). Ayrıca perihepatik sıvisı olan grupta kontrol grubuna göre daha fazla hastada laboratuvar değerlerinde yükseklik saptandı ( $p \leq 0.037)$. Hasta ve kontrol grubundaki laboratuvar değerleri ve serum değerlerinde yükselme saptanan olguların sıkığı Tablo 1'de gösterilmiştir.

Perihepatik sIVIsı olan 62 hastanın 32'sinde (\%51.6) intrahepatik safra kanallarında genişleme saptanırken kontrol grubunda 18 (\%29) hastada genişleme mevcuttu. iki grup arasındaki fark istatistiksel olarak anlamlı idi ( $p$ $=0.01)$. Hasta grubunda 62 hastanın 33'ünde (\%53.2) perisplenik sIVI, 19'unda (\%30.6) periportal ödem ve 12 'sinde (\%19.4) koledok taşı mevcuttu. Perihepatik sı-
Tablo 2. Hasta ve kontrol grubunda intrahepatik safra kanallarında genişleme, perisplenik sıvı, koledoktaşı ve periportal ödem varlığının sıklığı

\begin{tabular}{|lccc|}
\hline & \multicolumn{2}{c}{$\mathbf{n ( \% )}$} & \\
& Hasta & Kontrol & p \\
\hline IHSK genişleme & $32(51.6)$ & $18(29.0)$ & $\mathbf{0 . 0 1 *}$ \\
\hline Perisplenik sıvı & $33(53.3)$ & $3(12.0)$ & $<\mathbf{0 . 0 0 1 *}$ \\
\hline Periportal ödem & $19(30.6)$ & $8(12.0)$ & 0.065 \\
\hline Koledok taşı & $12(19.4)$ & $5(8.1)$ & 0.068
\end{tabular}

* Istatistiksel olarak anlamlı sonuçlar $(p<0.005)$

IHSK: Intrahepatik safra kanalları.

VISI olmayan kontrol grubunda ise $3(\% 12)$ hastada perisplenik sIvı, 8 (\%12) hastada periportal ödem, 5 (\%8.1) hastada koledok taşı saptandı. Perisplenik sıvı varlığının sıklığı iki grup arasında istatistiksel olarak farkı idi $(p<$ 0.001). Koledokta taş varlığı ve periportal ödem sıklığı açısından ise iki grup arasında anlamlı fark saptanmadı $(p \geq 0.065)$ (Tablo 2). Ayrıca perihepatik sıvıya eşlik eden periportal ödemi olan hastalarda periportal ödemi olmayanlara göre AST ve GGT değerlerinde yükselme istatistiksel olarak daha sık olup ( $p=0.007, p=0.012$, sırasıyla) bunlar dışındaki laboratuvar değerleri ile periportal ödem

\section{Tablo 3. Periportal ödem, perisplenik sıvı ve koledokta taş varlığı ile laboratuvar testleri arasındaki ilişki}

\begin{tabular}{|c|c|c|c|c|c|c|c|c|c|}
\hline \multirow[t]{2}{*}{$\begin{array}{l}\text { Laboratuvar } \\
\text { Testi }\end{array}$} & \multicolumn{3}{|c|}{$\begin{array}{l}\text { Periportal ödem } \\
\qquad(n, \%)\end{array}$} & \multicolumn{3}{|c|}{$\begin{array}{l}\text { Perisplenik Sivı } \\
\qquad(\mathrm{n}, \%)\end{array}$} & \multicolumn{3}{|c|}{$\begin{array}{l}\text { Koledok Taşı } \\
(n, \%)\end{array}$} \\
\hline & Hasta & Kontrol & $p$ & Hasta & Kontrol & $p$ & Hasta & Kontrol & $\mathbf{p}$ \\
\hline AST & $\begin{array}{c}15 \\
(78.9)\end{array}$ & $\begin{array}{c}18 \\
(41.9)\end{array}$ & $0.007^{*}$ & $\begin{array}{c}18 \\
(54.5)\end{array}$ & $\begin{array}{c}15 \\
(51.7)\end{array}$ & 0.824 & $\begin{array}{c}8 \\
(66.7)\end{array}$ & $\begin{array}{c}25 \\
(50.0)\end{array}$ & 0.299 \\
\hline ALT & $\begin{array}{c}14 \\
(73.7)\end{array}$ & $\begin{array}{c}21 \\
(48.8)\end{array}$ & 0.069 & $\begin{array}{c}18 \\
(54.5)\end{array}$ & $\begin{array}{c}17 \\
(58.6)\end{array}$ & 0.747 & $\begin{array}{c}9 \\
(75.0)\end{array}$ & $\begin{array}{c}26 \\
(52.0)\end{array}$ & 0.149 \\
\hline GGT & $\begin{array}{c}19 \\
(100.0)\end{array}$ & $\begin{array}{c}31 \\
(72.1)\end{array}$ & $0.012^{*}$ & $\begin{array}{c}27 \\
(81.8)\end{array}$ & $\begin{array}{c}23 \\
(79.3)\end{array}$ & 0.803 & $\begin{array}{c}10 \\
(83.3)\end{array}$ & $\begin{array}{c}40 \\
(80.0)\end{array}$ & 1.000 \\
\hline ALP & $\begin{array}{c}16 \\
(84.2)\end{array}$ & $\begin{array}{c}26 \\
(60.5)\end{array}$ & 0.065 & $\begin{array}{c}22 \\
(66.7)\end{array}$ & $\begin{array}{c}20 \\
(69.0)\end{array}$ & 0.847 & $\begin{array}{c}10 \\
(83.3)\end{array}$ & $\begin{array}{c}32 \\
(64.0)\end{array}$ & 0.306 \\
\hline LDH & $\begin{array}{c}5 \\
(26.5)\end{array}$ & $\begin{array}{c}7 \\
(17.9)\end{array}$ & 0.502 & $\begin{array}{c}7 \\
(21.9)\end{array}$ & $\begin{array}{c}5 \\
(19.2)\end{array}$ & 0.805 & $\begin{array}{c}3 \\
(25.0)\end{array}$ & $\begin{array}{c}9 \\
(19.6)\end{array}$ & 0.698 \\
\hline T. Bil & $\begin{array}{c}9 \\
(47.4)\end{array}$ & $\begin{array}{c}17 \\
(41.5)\end{array}$ & 0.668 & $\begin{array}{c}16 \\
(50.0)\end{array}$ & $\begin{array}{c}10 \\
(35.7)\end{array}$ & 0.265 & $\begin{array}{c}5 \\
(41.7)\end{array}$ & $\begin{array}{c}21 \\
(43.8)\end{array}$ & 0.896 \\
\hline D. Bil & $\begin{array}{c}16 \\
(88.9)\end{array}$ & $\begin{array}{c}31 \\
(77.5)\end{array}$ & 0.474 & $\begin{array}{c}27 \\
(84.4)\end{array}$ & $\begin{array}{c}20 \\
(76.9)\end{array}$ & 0.517 & $\begin{array}{c}10 \\
(83.3)\end{array}$ & $\begin{array}{c}37 \\
(80.4)\end{array}$ & 1.000 \\
\hline i. Bil & $\begin{array}{c}8 \\
(44.4)\end{array}$ & $\begin{array}{c}12 \\
(30.0)\end{array}$ & 0.284 & $\begin{array}{c}14 \\
(43.8)\end{array}$ & $\begin{array}{c}6 \\
(23.1)\end{array}$ & 0.099 & $\begin{array}{c}4 \\
(33.3)\end{array}$ & $\begin{array}{c}16 \\
(34.8)\end{array}$ & 1.000 \\
\hline
\end{tabular}

* İstatistiksel olarak anlamlı sonuçlar $(p<0.005)$

AST: Aspartat aminotransferaz, ALT: Alanin aminotransferaz, ALP: Alkalen fosfataz, GGT: Gamaglutamil transferaz, LDH: Laktat dehidrogenz T. Bil/D.Bil/I.Bil: Total/ Direkt/Indirekt bilirubin. 
bulgusu arasında ilişki saptanmadı ( $p>0.065)$. Perisplenik sıvı ve koledokta taş varlığı ile tüm laboratuvar testleri arasında ise herhangi bir ilişki saptanmadı ( $p>0.099, p>$ 0.149, sırasıyla) (Tablo 3).

Perihepatik sıvı kalınlığı ile laboratuar değerlerinin hiçbiri arasında korelasyon bulunmadı $(r<0.219, p>0.08)$. ALP dışında ( $r=0.349, p=0.05)$ diğer laboratuvar değerleri ile intrahepatik safra kanalları genişleme derecesi korelasyon göstermemekte idi ( $r<0.197, p>0.124)$ (Tablo 4).

Perihepatik sıvı en sık sol lob çevresinde (\%37.1) ve fokal patern şeklinde görüldü (\%54.8) (Resim1). Lokalizayon ve dağılım paterni sıklıkları Tablo 5'te gösterilmiştir.

Tablo 4. Perihepatik sıvı kalınlığı ve intrahepatik safra kanalları genișleme derecesi ile laboratuvar değerleri arasındaki korelasyon

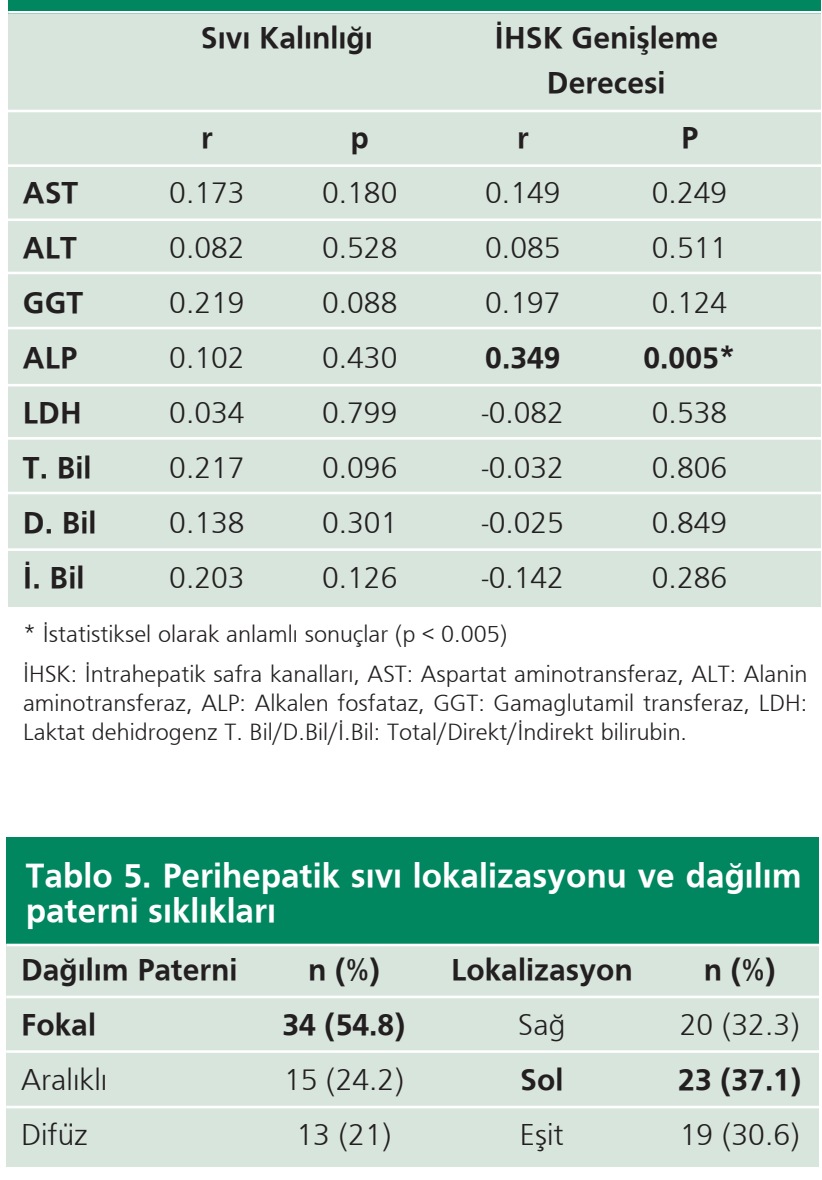

\section{TARTIŞMA}

Karaciğer ve karaciğer dışı patolojilere bağlı olarak görüntülemede perihepatik alanda Sıvı görülebilmektedir. Sıvı birikiminin nedenleri arasında tümör, safra sisteminde tıkanıklık, travma, otoimmün hastalıklar, kalp yetmezliği, enfeksiyon, apse, iatrojenik faktörler (ör; aşırı parasetamol kullanımı), toksinler ve siroz sayılabilir (2). Herhan- gi bir patolojiye spesifik olmayan bu bulgu değişik mekanizmalar ile oluşmaktadır. Akut veya kronik karaciğer hasarında, serum aminotransferaz (AST-ALT) konsantrasyonlarında artış ile karakterize hepatosellüler baskınlık meydana gelirken, biliyer kanaliküllerin hasar gördüğü durumlarda, safra kanalları epitelinde bulunan ALP ve GGT yükselmesi ile karakterize kolestatik baskınlık izlenir (12).

Bildiğimiz kadarıyla bugüne kadar perihepatik sıvı varlığı ile karaciğer fonksiyon testleri arasında ilişkiyi araştıran henüz bir çalışma yoktur. Erden A. ve ark.ları, daha az sayıda hastayı kapsayan çalışmalarında, kolestazlı olgularda perihepatik sıvının daha sık görüldüğünü belirlemişlerdir (13). Hasta sayısının daha fazla olduğu bu çalışmamızda ise perihepatik sIvısı olan hastalarda ALP ve GGT yanı sıra aminotranferaz değerlerinde de yükseklik saptanması ile bu bulgunun kolestaza spesifik olmadığını söyleyebilmekteyiz. Ancak perihepatik sıvısı olan hasta grubunda intrahepatik safra kanallarında genişlemenin daha fazla görülmesi ve intrahepatik safra kanallarındaki genişleme derecesi ile ALP değerinin korelasyon göstermesi perihepatik sıvı varlığının kolestazla da ilişkili olduğunu göstermektedir.

Perihepatik sıvı oluşumunda en önemli etkenlerden biri olan hepatik lenfatik dolaşım, derin (portal-sublobüler) ve yüzeyel lenfatikler olmak üzere iki ana gruba ayrılır. Karaciğer kapsülünden invajine olan bağ dokusu, portal triad (hepatik arter, portal ven dalları ve safra kanalları) boyunca uzanmakta ve yanı sıra lenfatik damarları da çevrelemektedir $(8,14)$. Hepatik lenf sıvısı, esas olarak hepatik sinüzoidlerden ve daha az miktarda da interlobüler safra kanallarının çevrili olduğu peribiliyer pleksustan kaynaklanır (15-17). Koledoğa retrograd reçine enjeksiyonu sonrası, hepatik lobul periferinde reçinenin safra kanallarından çıktığı ve portal trakt düzeyinde lenfatik damarlara geçtiği gösterilmiş olup bu durum safra kanalı obstrüksiyonunda safra içeriğinin lenfatik damarlara geçtiği gerçeğini desteklemektedir (6). Rosa G ve ark.'nın akut biliyer stazda hiperbilirübinemi ve enzim bozukluklarının mekanizmalarını araştırdığı, kedilerde yaptığı çalışma sonucunda da biliyer stazda safra ürünlerinin karaciğer lenfatikleri ve hepatik ven aracılığı ile eş zamanlı olarak kana ulaştığı, lenfatik sistem ve kanda ALP değerlerinde ılımlı düzeyde, transaminazlarda ise belirgin şekilde yükselme olduğu saptanmıştır (9). Çalışmamı biliyer obstrüksiyonun lenfatik sistem ve kandaki etkileri ile ilgili var olan bilgileri desteklemektedir.

Karaciğer çevresi peritoneal refleksiyon açısından zengindir ve karaciğer, komşuluğundaki anatomik yapılara ve ekstraperitoneal alanlara ligamentler ile bağlanır $(1,15)$. 
Çalışmamızda, bu bağlantılar ile perihepatik bölgede sıvı birikimine neden olabilecek durumlar (akut pankreatit, bilinen abdominal malignite) dışlanmıştır. Ayrıca kronik hepatit, karaciğer fibrozisi ve sirozda karaciğerde lenfanjiogenez artar (18). Bu nedenle bilinen kronik karaciğer hastalığı olan hastalar da çalışma dışında bırakılmıştır.

Lenfödemin görüntülenmesinde en yardımcı manyetik rezoanans (MR) sekanslarının 3D ağır T2 ağılıklı görüntülerin olduğu ortaya konmuştur. Ağır T2 ağıllıkı fast spin eko sekansı, zemin doku intensitesinde hemen tümüyle sinyal kaybına neden olarak uzun T2 relaksasyon süresi ile lenfatik damarların spesifik olarak görülmesini sağlayarak MR lenfanjiyogram elde edilmesine olanak sağlar (19). Bu nedenle ağır T2 ağırlıklı görüntülerde, miktarı çok az olan perihepatik sıviların saptanması mümkündür. Normal şartlarda kesitsel görüntülemede hepatik lenfatikler görülmezler. Anormal genişlemiş lenfatikler periportal alanlarda, bilgisayarlı tomografide (BT) lineer hipoatenüe, MR'da ağır T2 ağırlıklı sekanslarda lineer hiperintensiteler şeklinde görülür (20).

Çalışmamızda, perihepatik sıvı en sık sol lob çevresinde görülmüştür. Chen CJ ve ark.'nın hepatik subkapsüler sıvı

\section{KAYNAKLAR}

1. Lee JW, Kim S, Kwack SW, et al. Hepatic capsular and subcapsular pathologic conditions: demonstration with $C T$ and MR imaging. Radiographics 2008;28:1307-23.

2. Kim S, Kim TU, Lee JW, et al. The perihepatic space: comprehensive anatomy and CT features of pathologic conditions. Radiographics 2007;27:129-43.

3. Brink JA, Wagner BJ. Pathways for the Spread of Disease in the Abdomen and Pelvis. In: Hodler J, Kubik-Huch RA, von Schulthess GK, editors. Diseases of the Abdomen and Pelvis 2018-2021: Diagnostic Imaging - IDKD Book. Cham (CH): Springer; 2018. Chapter 6.

4. Barrowman JA. Hepatic lymph and lymphatics. In: Mclntyre N, Benhamou JP, Bircher J, Rizzetto M, Eds. Oxford Textbook of Clinical Hepatology. Oxford University Press, New York, 1991 (p.37-40).

5. Trutmann M, Sasse M. The lymphatics of the liver. Anat Embryol 1994;190:201-9.

6. Ohtani O, Ohtani Y. Lymph circulation in the liver. Anat Rec (Hoboken) 2008;291:643-52.

7. Popper $H$, Schaffner F. Liver structure and function. New York: McGraw-Hill 1957.

8. Ohtani Y, Wang BJ, Poonkhum R, Ohtani O. Pathways for movement of fluid and cells from hepatic sinusoids to the portal lymphatic vessels and subcapsular region in rat livers. Arch Histol Cytol 2003;66:239-52.

9. Rosa G, Segato G, Mantovani-Orsetti G, et al. The lymphatic system of the liver in the physiopathology of experimental acute cholestasis. VII. Cholesterol. Acta Chir Ital 1966;22(Suppl 2):295-302.

10. Alıcan F, Hardy JD. Lymphatic transport of bile pigments and alkaline phosphatase in experimental common duct obstruction. Surgery $1962 ; 52: 366-72$. koleksiyonları ile ilgili bir çalışmasında; bizim çalışmamızdan farklı olarak hastaların çoğunda sıvı koleksiyonunun sağ lob çevresinde olduğu bulunmuştur (21).

Çalışmamızın sınırlamaları, retrospektif olması yanı sıra hastaların tümünün aynı cihazda çekilememesi ve hastaların alkol tüketimi, bitkisel-tıbbi ilaç kullanımı, toksin maruziyeti gibi detaylı klinik bilginin elde edilememesidir.

Sonuç olarak MRKP'de karaciğer çevresinde minimal düzeyde sıvı varlığı karaciğer fonksiyon testlerinde bozukluğa işaret edebilir ve biliyer obstrüksiyona neden olabilecek patolojiler ve kolestaz ile ilişkili bulgular açııından uyarıcı olmalıdır.

Etik Kurul Onayı: Ankara Üniversitesi Tıp Fakültesi Klinik Araştırmalar Etik Kurulu'ndan 04-231-18 protokol numarası ile etik kurul onayı alınmıştır.

Çıkar Çatışması: Yazarlar herhangi bir çıkar çatışması beyan etmemişlerdir.

Finansal Destek: Yazarlar finansal destek beyan etmemişlerdir.
11. Cameron GR, Muzaffar HS. Disturbances of structure and function in the liver as the result of biliary obstruction. J Pathol Bacteriol 1958;75:333-49.

12. Giannini EG, Testa R, Savarino V. Liver enzyme alteration: a guide for clinicians. CMAJ 2005;172:367-79.

13. Erden A, Orgodol H, Savran B, Erden İ. Karaciğer enzim düzeyleri ile perihepatik sıvı prevelansı arasındaki ilişkinin değerlendirilmesi. 30. Ulusal Radyoloji Kongresi, TURKRAD 2009, 4-9 Kasım, Antalya.

14. Rappaport AM. Diseases of the Liver. In: Schiff L Eds. Anatomic considerations. 2nd Edition, Lippincott Company-Asian Edition Hakko Co. Ltd., Philadelphia, 1-46.

15. Collins JD, Disher AC, Shaver ML, Miller TQ. Imaging the hepatic lymphatics: experimental studies in swine. J Natl Med Assoc 1993;85:185-91.

16. Deimer EE. Lymphatic anatomy. In; Clinical radiology of the liver, p. 55. Edited by $H$. Herlinger $H$, Lunderquist A, Wallace S. Marcel Dekker, New York, 1983.

17. Ohtani O, Murakami T. Peribiliary portal system in the rat liver as studied by the injection replica scanning electron microscopic method. Scanning Microsc 1978: 241-4.

18. Barrowman JA, Granger DN. Effects of experimental cirrhosis on splanchnic microvascular fluid and solute exchange in the rat. Gastroenterology 1984;87:165-72.

19. Arrivé L, Derhy S, Dlimi C, et al. Noncontrast magnetic resonance lymphography for evaluation of lymph node transfer for secondary upper limb lymphedema. Plast Reconstr Surg 2017;140:806e-11e.

20. Koslin DB, Stanley RJ, Berland LL, et al. Hepatic perivascular lymphedema: CT appearance. AJR Am J Roentgenol 1988;150:111-3.

21. Chen CJ, Chang WH, Shih SC, et al. Clinical presentation and outcome of hepatic subcapsular fluid collections. J Formos Med Assoc 2009;108:61-8. 